Geograficando, vol. 15, n. ${ }^{\circ}$ 1, e050, mayo-octubre 2019. ISSN 2346-898X

Universidad Nacional de La Plata.

Facultad de Humanidades y Ciencias de la Educación.

Departamento de Geografía

\title{
Conflictividad territorial en Chubut: una lectura en torno a los movimientos ambientalistas
}

Territorial conflicts in Chubut: a reading regarding environmental movements.

\section{Cristian Hermosilla Rivera}

Departamento de Geografia - FHCS -

Universidad Nacional de la Patagonia, Argentina

cristianhermosillarivera@gmail.com

\section{Resumen:}

A diferencia del abordaje académico hegemónico, que visibiliza el inicio de la lucha ambiental en Chubut con el No a la Mina en Esquel de 2003, este trabajo intenta demostrar que el movimiento ambiental emergió como sujeto político provincial determinante hace aproximadamente 40 años. Y, sobre todo, que no puede analizarse sin entender las luchas previas, sean sindicales, sociales o políticas, en línea con el contexto nacional y mundial, es decir, con los modos de acumulación dominantes y la estructuración ideológico cultural de cada época. Por lo tanto, el éxito de la lucha ambiental no puede abordarse como obra de aislados y nuevos movimientos sociales, tal como expresan las teorías hegemónicas del individualismo metodológico o la acción colectiva, sino como consecuencia del complejo movimiento de la sociedad, a partir de las contradicciones que genera el capitalismo en sus diversas escalas.

Palabras Clave: Megaminería, Chubut, Territorio, Movimientos ambientales.

\section{ABstract:}

Unlike the hegemonic academic research, which makes the begin of the environmental struggle in Chubut with of the "No" to the Mine of Esquel in 2003 visible, this paper will try show that social movement appeared like a decisive provincial political approximately 40 years ago. And, above all, it tries to show that it cannot be analyzed without understanding the previous struggles, whether they are union, social or politic, in line with national and international contexts, that is, with the dominant modes of accumulation and the ideological-cultural structuration of each epoch. Therefore, the success of the environmental struggles cannot be addressed as the work of isolated or new social movements, as expressed by the hegemonic theories of methodological individualism or collective action, but as a consequence of the complex movement of society, based on the contradictions generated by capitalism at its various scales.

KEYWORDS: Mega-mining, Chubut, Territory, Environmental movements.

\section{INTRODUCCIÓN}

A partir de la consolidación del Estado en Patagonia, a fines de siglo XIX, la región se estructuró en base a una economía capitalista de enclave, con ciudades orientadas a facilitar la extracción de naturaleza sin mayor valor agregado: lana, petróleo, gas, uranio y carbón, entre otros. Lejos de dejar atrás este modelo productivo que se fue desarrollando con diversos matices durante el siglo XX, la provincia se proyecta en la actualidad, a partir de la implementación de políticas neoliberales, como una región clave en el contexto nacional e internacional según los parámetros valorativos del capital financiero. Esto es así porque posee grandes yacimientos metalíferos de oro, plata y uranio, como así también yacimientos petroleros y gasíferos en formaciones de esquistos, explotables por medio de la fractura hidráulica o fracking. La posibilidad de profundizar el modelo es viable gracias a los avances tecnológicos actuales, que permiten que minerales con baja densidad de concentración hoy sean económicamente rentables. El Fraser Institute de Canadá, prestigiosa entidad de investigación económica y considerada el termómetro del clima inversor a nivel mundial, posiciona a la provincia en el noveno lugar del ranking mundial en cuanto a potencial minero y como número uno a la hora de analizar las áreas mineras con mayores posibilidades de desarrollo de la República Argentina. Además la provincia cuenta, en conjunto con la región patagónica, con bienes 
estratégicos claves para el futuro de la humanidad, como reservas de agua dulce superficial, subterránea y glacial, potencial eólico y compleja biodiversidad.

Pero los costos sociales, económicos y ambientales que los diversos modelos de acumulación generaron a escala planetaria, han hecho emerger un conjunto de organizaciones de la sociedad civil, que si bien componen un arco heterogéneo, han logrado frenar la profundización y sofisticación de un modelo que históricamente ha imperado en Patagonia. Hasta el momento no parece haber un proyecto alternativo claro pero, como idea fuerza, existe consenso en la necesidad de pensar en otros tipos de territorios, que sean la base de alternativas sustentables desde lo ambiental y equitativas desde lo social. Aun así estas luchas han hecho fracasar, una y otra vez, los intentos de diversos gobiernos nacionales y provinciales de profundizar la matriz extractivista en la región, dejando entrever que las resistencias a dicho modelo, muchas veces subestimadas, tienen un basamento considerablemente sólido. Tal es así, que el poder económico y político vuelve permanentemente sobre sus pasos para imponer el modelo, poniendo en juego nuevas y sofisticadas estrategias de consenso y coerción.

¿Pero qué factores se han combinado en Chubut, una provincia relativamente pequeña en términos poblacionales, para que la lucha social haya impedido durante tanto tiempo la instalación de los proyectos de los capitales transnacionales mineros? ¿Qué lectura teórica se puede realizar al margen de las corrientes hegemónicas que abordan a los movimientos sociales desde corrientes teóricas como la acción colectiva y el individualismo metodológico?

Estas preguntas, de difícil resolución, se orientan a entender por qué Chubut ha sido la excepción o la anomalia en esta fase del imperialismo neoliberal en Patagonia y en Latinoamérica. Este trabajo intenta abrir algunos debates abordando, desde el materialismo histórico, las características de las luchas y rebeliones sociales que se han suscitado en el marco de las contradicciones sociales y ambientales, contextualizándolas en el marco de la lucha social amplia e histórica, y no como una novedad que aparece en escena con los movimientos asamblearios post crisis de 2001. A diferencia del abordaje académico hegemónico, que visibiliza la lucha ambiental recién a partir del siglo XXI con los sucesos del No a la mina en Esquel en el año 2003, este trabajo intenta demostrar que el movimiento ambiental emergió como un sujeto político provincial determinante hace más de 40 años. Y, sobre todo, que no puede analizarse sin entender las luchas previas, sean sindicales, sociales o políticas, en línea con el contexto nacional y mundial, es decir, con los modos de acumulación dominantes y la estructuración ideológico cultural de cada época. Por lo tanto, el éxito de la lucha ambiental no puede abordarse como obra de aislados y nuevos movimientos sociales, como sujetos aislados y fenoménicos, tal como expresan las teorías hegemónicas basadas en el individualismo metodológico o la acción colectiva. Estos dejan de lado las contradicciones socioambientales, los análisis clasistas o los impactos de los modelos de acumulación en los movimientos de la sociedad.

Muchos de los trabajos que abordan la movilización social ambientalista lo hacen con el foco puesto en la megaminería, luchas que ciertamente emergen con una fuerza sin precedentes a principios del siglo XXI, pero lo hacen aportando (con o sin intención) a una visión que parcializa el origen de la conflictividad ambiental. Es decir, se asocian las resistencias contra la megaminería con la aparición del sujeto ambiental en las postrimerías del siglo XX y los albores del nuevo siglo. Sin negar la importancia de lo sucedido en Esquel (2003), se terminan negando o eclipsando las luchas ambientales que lo anteceden, como así también los procesos económicos, sociales y culturales previos que dieron lugar a dichas resistencias. Es decir, en el afán de buscar la novedad, aquellos trabajos terminan fragmentando binariamente entre viejos y nuevos movimientos sociales, resaltando la novedad del sujeto ambiental y opacando las históricas luchas sociales.

\section{Emergencia del movimiento ambiental en Chubut}

En Chubut, la construcción social de la conciencia ambiental, y el sujeto ambiental que la encarna, se puede rastrear desde mediados y fines de la década del 70, siendo clave el movimiento contracultural que 
migró de los grandes centros urbanos hacia la Comarca Andina, denominación que se da al sector que comparten el noroeste de Chubut (departamento Cushamen -ver Figura1-) y el suroeste de Río Negro. No se deben abordar como un fenómeno que ocurrió por decisiones aisladas de un grupo, sino como "consecuencia de un modo de acumulación dominante y de la construcción ideológico-cultural de la época”.(Galafassi, 2014, p. 63).

FIGURA 1:

Departamentos, localidades y cuenca del río Chubut.

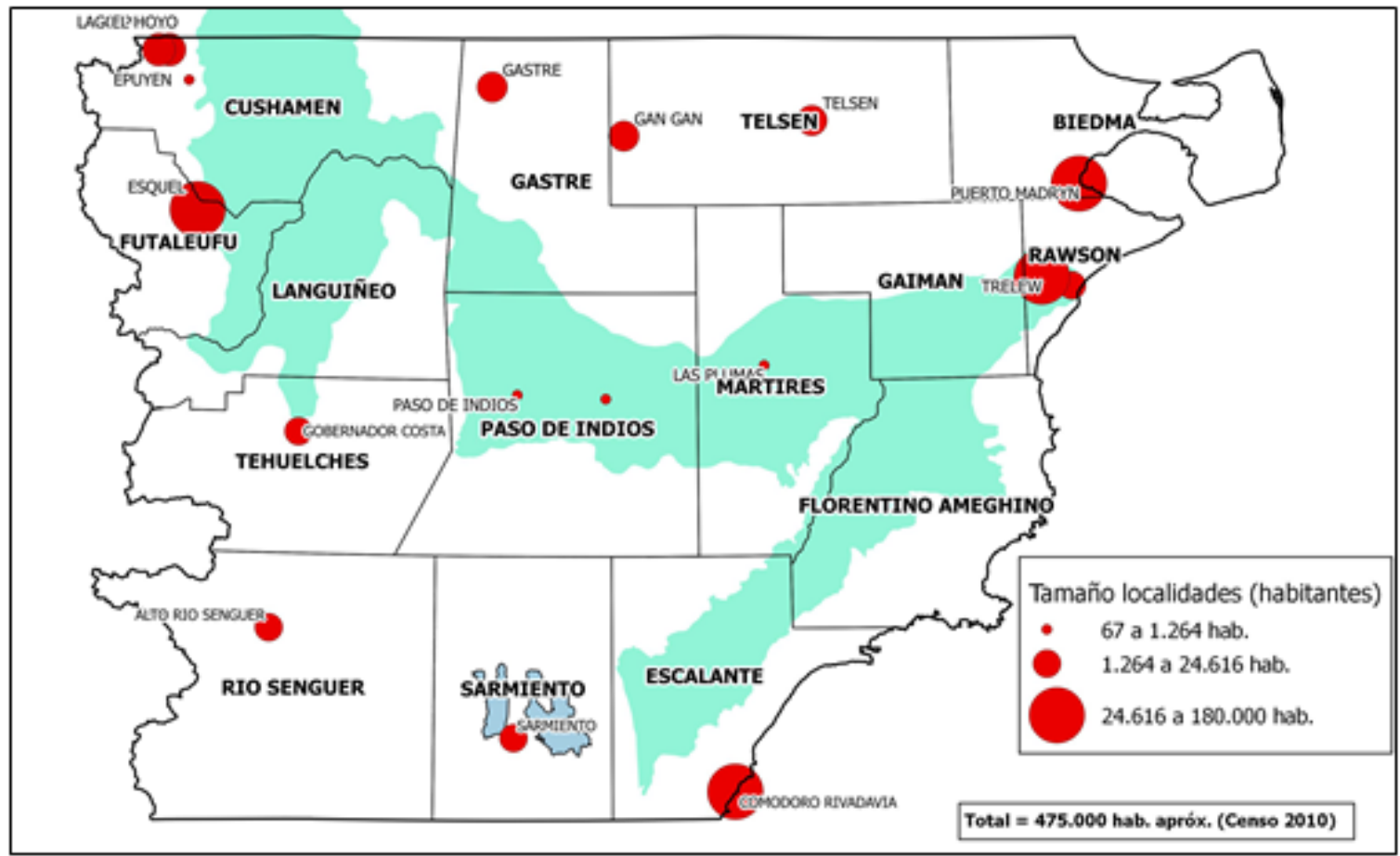

Elaboración propia

El movimiento contracultural nacido en Europa y Estados Unidos a fines de la década del 60 será entonces una de las claves para entender el proceso que dio origen al movimiento ambiental en Chubut. Pero ello confluyó con contextos locales, propios de América Latina, donde los procesos de conflictividad social alternaron o convivieron con regímenes dictatoriales. De acuerdo a entrevistas a referentes claves realizadas en este trabajo se puede decir que el movimiento contracultural, o hippismo como comúnmente se lo denomina en Argentina, estuvo lejos de ser sólo una idea romántica en busca de una vida cercana a la naturaleza y a la autosuficiencia comunitaria. Puede decirse que fue consecuencia, por un lado, a las resistencias de los valores capitalistas (aunque también del campo soviético), y por el otro, de la formación intelectual y el activismo social y ecológico que se fue gestando al interior de dicho movimiento, como respuesta a las contradicciones sociales y ambientales de la época.

En Argentina, un gran sector de estos movimientos contraculturales eligió migrar hacia la Comarca Andina. Esto se relacionó con la necesidad de escapar de los grandes centros urbanos, de la alienación y consumismo que allí se imponía, pero también para alejarse de los marcos represivos de la dictadura militar en el campo de la cultura y la política. La cordillera funcionó de esta manera como el lugar donde era posible desarrollar ciertas prácticas culturales, debido a la lejanía y a las condiciones naturales, relativamente poco explotadas en aquella época.

Lucas Chiappe, referente del movimiento contracultural e impulsor de la Comisión de Defensa del Valle de Epuyén (departamento Cushamen), conformada para frenar la construcción de un dique y la consecuente inundación del valle expresa que, previo a su llegada a la región en 1976, ya venía desarrollando 
su conciencia ecológica por diversas vías. No a pesar, sino a causa de la dimensión ecológica del hippismo. Sus viajes por el mundo, su participación en una importante revista cultural de tirada nacional, y su lectura de pensadores ligados al ecologismo fueron, en parte, las claves para motivar su posterior lucha local contra la deforestación que estaban causando las madereras, contra las consecuencias irreversibles del proyecto del dique ya mencionado y contra la fallida instalación del repositorio nuclear en Gastre. Como se expresó anteriormente, su elección por Epuyén se relacionó con la necesidad de escapar de los marcos represivos de la última dictadura, llegando incluso a estar en una lista negra por el sólo hecho de tener el pelo largo. En tanto, Oscar Silberman, otro referente contracultural, y militante de la lucha contra el basurero nuclear en Gastre y contra la proliferación de la energía nuclear, se estableció en El Bolsón a inicios de los 80, pero ya participaba activamente en el ecologismo del conurbano bonaerense, concretamente en el Centro de Protección de la Naturaleza, una de las instituciones más importantes de la época a nivel nacional. Al igual que Chiappe, participó en espacios académicos-culturales que abordaban la problemática del medioambiente como eje fundamental. Por ejemplo, participó en la revista Mutandia, la cual tenía una columna dedicada al ecologismo y a través de la cual se conocieron y difundieron ideas de importantes intelectuales ecologistas de la época, a pesar del cerrojo que imponía la dictadura. Al establecerse definitivamente en la Comarca Andina, impulsó la conformación de una delegación del Centro de Protección de la Naturaleza, que luego se convertiría en la Sociedad Ecológica Regional, experimentando un inmediato crecimiento e influencia en la zona, en gran medida por el interés que la comunidad ya tenía por los temas ecológicos.

Estos dos casos son paradigmáticos, ya que permiten comprender la experiencia de otras tantas personas que conformaron el sujeto contracultural con conciencia ambiental en la región. De acuerdo a estas y otras fuentes, se puede afirmar que la lucha ambiental emerge, con niveles organizacionales sin precedentes, a fines de la década del 70 y principios de los 80 , con procesos exitosos contra la tala indiscriminada de bosques, la utilización de agentes químicos en áreas urbanas, la conformación de Municipios No nucleares, el dique en Epuyén, etc.

Por lo tanto, en cuanto al crecimiento o influencia, se puede decir que a principios de los 80 el sujeto ambiental emerge con fuerte influencia regional en la Comarca Andina. En tanto que la influencia provincial se irá gestando a mediados de los 80 , gracias a la lucha de estos mismos grupos contra el proyecto del repositorio nuclear en la localidad de Gastre, cabecera del departamento homónimo (ver Figura 1).

Dos casos indican que el movimiento ambiental no salió del marco regional de la Comarca Andina sino hasta mediados de la década del 80. El primero fue la instalación de ALUAR en la ciudad de Puerto Madryn. Dicha empresa fue inaugurada casi sin resistencia de grupos ambientalistas en 1974, y continúa en funcionamiento hasta la actualidad. Se trata de una de las empresas productoras de aluminio primario más grandes de Latinoamérica, y es un secreto a voces que emite periódicamente más fluoruro de lo permitido, además de estar comprobado que ha tenido sus cubas a cielo abierto desde 1974 hasta principios de la década del 90. Como corolario, en 1978 se inaugura la Central Hidroeléctrica de Futaleufú para dar plena utilización de la capacidad instalada en la planta de Madryn, lo cual también implicó un gran impacto ambiental en dicha cuenca. Otro caso a mencionar es aquel relacionado con la explotación de uranio a cielo abierto, entre 1976 y 1977, en la localidad de Los Adobes, departamento de Paso de Indios (ver figura 1), y a escasos metros del río Chubut que abastece de agua a todo el Valle Inferior (Trelew, Rawson, Gaiman, entre otras), incluida la ciudad de Puerto Madryn. Si bien es una hipótesis contra fáctica, el hecho de que estos dos proyectos hayan podido convertirse en realidad se debe a que, al momento de sus materializaciones, los movimientos ambientales aún no habían germinado a escala provincial. Hasta ese momento, la experiencia gestada en la Comarca Andina sólo tenía impacto en la escala local, es decir, en sus pueblos y alrededores. Con el recorrido y el crecimiento de la conciencia de la población en años posteriores es casi imposible que dichas actividades, con un impacto ambiental tan grande, hubieran podido instalarse sin resistencias o conflictos de envergadura en la década del 80, y mucho menos en la década del 90, momento en que las organizaciones ya tenían un fuerte desarrollo provincial. 
En 1986, año de la primera gran marcha a la localidad de Gastre contra el repositorio nuclear, es que el movimiento ambiental se ramifica, pasando de intervenciones locales en la Comarca Andina, a tener influencia a escala provincial. Se debe aclarar que la lucha contra el repositorio tiene dos etapas, una que se cierra en 1986 y otra en 1996, ambas con multitudinarias marchas y ya con fuerte participación de la población proveniente de las grandes ciudades de la costa y la cordillera. La segunda etapa de estas luchas contra el repositorio fue la que terminó de consolidar la conciencia ambiental en toda la provincia, especialmente en el noreste del Chubut (departamentos Rawson y Biedma), es decir, la región más densamente poblada de la provincia, y en la que se encuentran centros urbanos como Trelew, Puerto Madryn y Rawson.

Como se puede observar, los sucesos del No a la Mina en Esquel en 2003 aparecen en un contexto mucho más complejo, integrado a la historia de lucha regional, como resultado de un acumulado de experiencias que se inician con las experiencias en la Comarca Andina y que maduran con los hechos de Gastre. No aparece escindido de procesos previos, ni por migrantes descontextualizados de los modos de acumulación. Sin duda el liderazgo carismático de algunas/os ambientalistas es imprescindible en estas luchas, pero debe comprendérselas/os como producto y no como productor de dichos contextos. En este sentido no puede soslayarse el contexto internacional de fines de la década del 60, el cual propició la aparición de los movimientos contraculturales que pusieron, entre otros temas, lo ambiental o lo ecológico en la agenda política.

La correlación sujeto/estructura vuelve así a cobrar importancia a la hora de interpretar los procesos sociales. En un intento por interpretar la movilización social a la luz de las contradicciones del capitalismo, trazando un paralelismo entre el histórico movimiento obrero (viejos movimientos sociales) y los denominados nuevos movimientos sociales, el próximo apartado intentará dar algunas herramientas para abordar el contexto del período bajo estudio, tanto a escala general como local. Este pareciera entonces ser un camino mucho más productivo que aquel seguido por el individualismo metodológico "que define un corte abrupto entre viejos y nuevos movimientos quitándole a su vez el carácter dialéctico a la dinámica social."(Galafassi, 2012b, p. 26).

\section{Discusiones geNERALES EN TORNO A LAS CONTRADICCIONES DEL CAPITALISMO}

De acuerdo con las experiencias abordadas por otros autores/as, se partirá de la premisa de que Patagonia, y Chubut específicamente, no está frente a una novedad cuando se habla de neo extractivismo, sino a una profundización y sofisticación de la matriz con la cual fue pensada y explotada desde fines de siglo XIX. Esta orientación productiva fue proyectada por la clase dominante nacional de la época, la cual acepto un rol de exportador de naturaleza en la división internacional del trabajo. Patagonia, claro está, aportó la producción lanar y posteriormente el petróleo que comenzó a tener gran valor comercial en el mercado mundial. En la década del 50 se impondrá una política desarrollista en algunos puntos de Patagonia, materializándose en la creación de polos industriales, pero dicho modelo terminó de agotarse en la década del 90, a medida que la burguesía financiera logró hegemonizar la estructura económica social de Argentina. La explotación a gran escala de la naturaleza en sus diversas formas (grandes pools de soja, petróleo convencional y en esquistos, uranio, plata, oro, el recurso ictícola del mar Argentino e incluso el turismo), se convirtió en el modelo imperante hasta la actualidad.

Claro está que estos modelos de acumulación no se han originado endógenamente ni aisladamente en la región, sino que han sido el resultado de históricas disputas interburguesas en el plano nacional e internacional. Por ello es necesario entender esta relación multiescalar de las burguesías, lo que a su vez conlleva a reconocer impacto del imperialismo desde aquel fin de siglo XIX hasta la actualidad.

De acuerdo con las experiencias abordadas por otros autores/as, se partirá de la premisa de que Patagonia, y Chubut específicamente, no está frente a una novedad cuando se habla de neo extractivismo, sino a una 
profundización y sofisticación de la matriz con la cual fue pensada y explotada desde fines de siglo XIX. Esta orientación productiva fue proyectada por la clase dominante nacional de la época, la cual acepto un rol de exportador de naturaleza en la división internacional del trabajo. Patagonia, claro está, aportó la producción lanar y posteriormente el petróleo que comenzó a tener gran valor comercial en el mercado mundial. En la década del 50 se impondrá una política desarrollista en algunos puntos de Patagonia, materializándose en la creación de polos industriales, pero dicho modelo terminó de agotarse en la década del 90, a medida que la burguesía financiera logró hegemonizar la estructura económica social de Argentina. La explotación a gran escala de la naturaleza en sus diversas formas (grandes pools de soja, petróleo convencional y en esquistos, uranio, plata, oro, el recurso ictícola del mar Argentino e incluso el turismo), se convirtió en el modelo imperante hasta la actualidad.

Claro está que estos modelos de acumulación no se han originado endógenamente ni aisladamente en la región, sino que han sido el resultado de históricas disputas interburguesas en el plano nacional e internacional. Por ello es necesario entender esta relación multiescalar de las burguesías, lo que a su vez conlleva a reconocer impacto del imperialismo desde aquel fin de siglo XIX hasta la actualidad.

En la actualidad, y desde la década del 70 el mundo presencia un nuevo tipo de imperialismo que la hegemonía intelectual ha intentado disfrazar con diversas acepciones, entre ellas globalización.

La globalización no es el fin del imperialismo sino un salto cualitativo del mismo, al cual nos referiremos a continuación. Representa la transición del imperialismo clásico hacia otro de nuevo tipo, basado en las actuales condiciones bajo las cuales se desenvuelve el modo de producción capitalista. (Borón, 2013, p. 21).

Para David Harvey (2007) este nuevo tipo de imperialismo, producto del dominio de la burguesía financiera, prioriza una estrategia de acumulación mediante el despojo (a través de las privatizaciones, principalmente) por sobre la reproducción ampliada (propia del keynesianismo post Segunda Guerra Mundial). Esto no quiere decir que durante el imperialismo norteamericano que va de 1945 a 1973 no haya existido el pillaje, la violencia o el despojo, sino que simplemente no era la estrategia central de la burguesía hegemónica. Por ello, el autor expresa que es necesario reevaluar las hipótesis que relegan la acumulación basada en la depredación, el fraude y la violencia a una etapa original del capitalismo.

De acuerdo con Harvey, se puede decir que el nuevo imperialismo viene a superar la brutalidad del despojo social y ambiental que mostraron tanto el modelo imperialista bajo hegemonía británica, basado en la autarquía de las burguesías europeas y el saqueo a sus colonias (1884-1945), como al proyecto imperialista bajo hegemonía estadounidense, basado en la reproducción ampliada del capital / keynesianismo (1945-1973). Es a partir de la década del 70 entonces, y debido al estancamiento económico originado por la sobreacumulación capitalista mundial, que Estados Unidos intenta una salida a la crisis mediante un sistema basado en nuevos acuerdos internacionales y financieros institucionales, centrando nuevamente el poder económico en el capital financiero, con sede en Wall Street. Todo esto implicó un cambio en la correlación de poder dentro de las diversas burguesías mundiales, mediante el cual los sectores productivos perdieron preponderancia frente a las instituciones del capital financiero.

Así, el capital financiero fue central para esta tercera fase del dominio global burgués (...) La acumulación por desposesión se convirtió en un rasgo mucho más central dentro del capitalismo global (con la privatización como uno de sus principales mantras) (Harvey; p.118).

Cada uno de estos modelos de acumulación ha presentado sus contradicciones y sus crisis, entendiendo que en el capitalismo las crisis son sistémicas y han atravesado los diversos imperialismos, sin excepción. Pero las características de las contradicciones que está generando el nuevo imperialismo, cada vez más profundas, tanto desde lo social como de lo ambiental, generan un contexto de lucha de clase más complejas que aquellas que emergieron en gran parte del siglo XX.

Esto es muy distinto a decir que el movimiento obrero y sus formas tradicionales de lucha han perdido peso o que fueron reemplazados por los nuevos movimientos sociales. No hubo reemplazos, sino la complejización de la lucha contra los ajustes del capital (Pérez Álvarez, 2013). 
Para poder abordar esta complejidad, James O'Connor (2001) y Bellamy Fosters (1992) expresan que estas luchas deben ser abordadas de manera compleja, teniendo en cuenta que al movimiento obrero, sujeto político revolucionario surgido de la primera contradicción (entre fuerzas y relaciones de producción), se le suman los movimientos sociales, sujetos políticos surgidos de la segunda contradicción del capitalismo (apropiación y uso destructivo, por parte del capital, de la fuerza de trabajo, la infraestructura, el ambiente, etc.), los cuales emergen con fuerza a partir de la década del 60.

Como expresa $\mathrm{O}^{\prime}$ Connor, el marxismo tradicional esclarece las prácticas de los movimientos laborales tradicionales, y de manera similar el marxismo ecológico puede esclarecer las prácticas de los movimientos sociales. Entonces, comprender estas contradicciones y los sujetos que la encarnan son claves para comenzar a abordar la situación chubutense. No es el objetivo de este trabajo responder cabalmente a estas cuestiones, sino rastrear algunas dimensiones que dieron origen al sujeto de la lucha ambiental, a fines de la década del 70 , y el consenso que han construido hasta la actualidad. Para ello es necesario comprender el impacto de las políticas económicas nacionales e internacionales en el marco regional, a partir del cual se podrá entender la actualidad de un movimiento ambiental chubutense que, post 2003, se potenció gracias a la conjunción con el movimiento obrero/sindical, organizaciones sociales y vecinos/as autoconvocados/as, entre otros.

\section{Modelos de ACUMulación y CONFlictividad social en Chubut}

Con diversos matices en cuanto a las estructuras económico sociales a lo largo de las distintas décadas y regiones, la orientación productiva de Patagonia impuesta desde fines del siglo XIX ha ido al compás de las reconfiguraciones imperialistas, aunque nunca varió su carácter de exportadora de naturaleza sin mayor valor agregado. Esto deja en evidencia que el modelo extractivo no es exclusivo de la actualidad, sino que ha sido consustancial al proceso de conquista y colonización de América Latina (Galafassi y Riffo, 2018).

A su vez, esto echa por tierra la idea de que Patagonia es una región marginal en el plano nacional e internacional. Más bien ocupa un lugar importante en el debate político de las burguesías nacionales e internacionales por poseer bienes naturales claves y aún sin explotar bajo las nuevas tecnologías productivas. La posibilidad de explotar minerales que, hasta hace unas décadas, eran poco rentables por su dispersión, o porque simplemente abundaban en otros puntos del planeta, ha abierto el apetito de las grandes transnacionales que esperan con ansias el definitivo cercamiento de la región.

Si en la actualidad se tiene en cuenta la experiencia petrolera con modalidad fracking en Neuquén, y la minería metalífera a cielo abierto en Río Negro y Santa Cruz, se puede decir que Chubut sigue siendo una anomalía o excepción para el capital transnacional minero, ya que la maquinaria del consenso y la coerción no ha podido generar la licencia social necesaria. Muy por el contrario, las resistencias en Chubut son cada vez mayores, lo que representa un territorio difícil de abordar o cercar para el provecho del capital. Cabe aclarar que cuando en este trabajo se habla de anomalía o excepción, es sólo para referir a la imposibilidad del capital megaminero de penetrar en la provincia, pero no para catalogar de esta manera a las resistencias y las luchas sociales, tal como en la actualidad lo hacen las corrientes posmodernas, las cuales entienden que el estado normal de una sociedad es la armonía o la protesta por canales tradicionales. La crisis no es algo extraño o rupturista con respecto al sistema, sino que el sistema capitalista vive y se reproduce en una constante situación de crisis latente; por ende las crisis no tampoco son una excepción o anomalía del sistema capitalista; más bien son la manifestación última de las contradicciones capitalistas, momentos en los cuales el capitalismo se transforma a sí mismo para intentar resolverlas.

Una de las claves para responder al por qué la provincia del Chubut no ha podido ser sometida al mandato del capital minero puede estar en el abordaje del movimiento de la sociedad chubutense, sobre todo en su región septentrional. Pérez Álvarez (2013) analiza exhaustivamente los cambios en la estructura económica social y los conflictos sociales en el noreste del Chubut. Por supuesto que esta región tiene particularidades respecto al resto de la provincia, pero también es posible entender el resto de la provincia a partir del noreste. 
Esta afirmación se basa en que este es lugar donde se afinca la clase política dominante a nivel provincial, histórica subsidiaria de la burguesía nacional y, por ende, donde se digitan las decisiones políticas de mayor importancia provincial. También donde en general se han originado los conflictos sociales de mayor peso político e histórico.

El autor destaca que se han desencadenado tres tipos de estructura económica social, el capitalismo de economía privada (1865-1850), el capitalismo de Estado en enclaves (1950-1980) y una articulación entre el capitalismo de Estado en enclave de grandes empresas privadas (1980 hasta la actualidad), lo cual coincide a grandes rasgos con las configuraciones del capitalismo mundial.

El período del capitalismo de Estado en enclave (1950-1980) es una de las claves para entender las conflictividades sociales en la región, ya que en dicho contexto se originó la llegada masiva de migrantes, atraídos por la promoción industrial y por la dinámica que esta generó sobre resto de las actividades económicas. En la figura 1 puede observarse que, salvo el departamento Escalante, donde se encuentra la ciudad de Comodoro Rivadavia, el resto de los departamentos urbanos de la provincia tuvieron su explosión demográfica entre 1950 y 1980.

FIGURA 2:

Población por departamentos

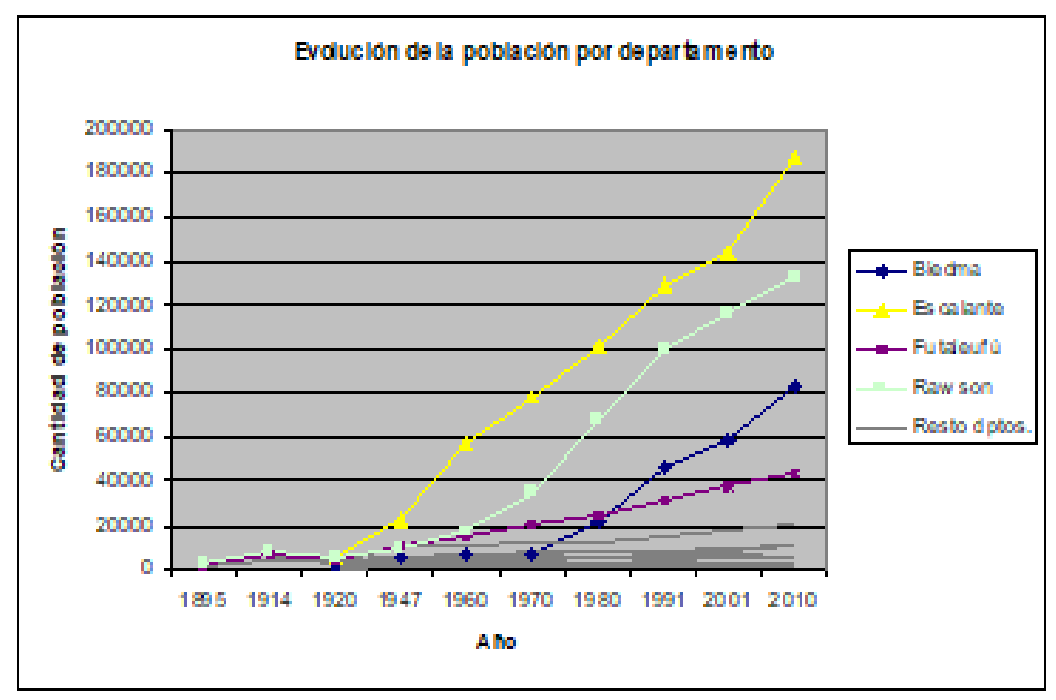

Fuente: Hermosilla Rivera (2013)

Volviendo al período 1950-1980, y al realizar un detalle del crecimiento poblacional por regiones, se hace evidente la relación entre la estructura económica social y el crecimiento demográfico. Por ejemplo, en la figura 1 puede observarse que el noreste del Chubut (departamentos Biedma y Rawson) tuvo un crecimiento exponencial entre 1960 y 1970, a partir de la instalación de las industrias textiles, principalmente en Trelew, y de ALUAR en Puerto Madryn. El noroeste (departamentos Cushamen y Futaleufú, en el cual se encuentra Esquel) en cambio no ha sufrido explosión demográfica como el noreste, aunque nunca ha dejado de crecer a tasas estables, sobre todo a partir de 1950. Si bien no entra en el análisis de este trabajo, cabe destacar la situación de Comodoro Rivadavia (departamento Escalante), ya que tuvo una dinámica demográfica distinta al resto, con una explosión más temprana, de la mano de la explotación del petróleo, sobre todo a partir de la década del 20 con la creación de YPF.

Se deben hacer dos salvedades, la región bajo análisis en este trabajo es la región septentrional del Chubut, es decir, noroeste (y su comarca andina), la meseta central y el noreste del Chubut, considerando que este conjunto regional es clave para abordar el origen y desarrollo del movimiento ambiental provincial. Por el otro, la comarca andina es un territorio que comprende no sólo a la provincia del Chubut, sino parte de Río Negro, lo cual complejiza el análisis, ya que ciudades como El Bolsón han sido claves en la génesis del 
movimiento ambiental. Aun así, no deben hacerse lecturas fragmentadas, sino entender las particularidades de cada región en un contexto global.

El impacto de la migración que llegó a la provincia debe leerse en términos cualitativos, ya que modificó la dinámica de las relaciones de fuerza sociales que existían previa aplicación de la política desarrollista. Los nuevos sujetos políticos que emergen en esta época, como el movimiento obrero/sindical y el incipiente movimiento contracultural/ecologista, tuvieron una extracción cultural y social muy heterogénea. En el primer grupo se pueden contar migrantes del norte del país, limítrofes, trabajadores rurales de la meseta, muchos de ellos pertenecientes a comunidades mapuche-tehuelches (Pérez Álvarez, 2013). En tanto que, en sus orígenes, el segundo grupo tuvo una extracción de clase más ligada a la pequeña burguesía, comúnmente denominada clase media, algunos/as de los/as cuales ya tenían trayectorias en los ámbitos artístico/culturales, ambientales o políticos antes de su llegada a la región. Territorialmente, y debido al lugar dónde se desarrolla en mayor grado, podría decirse que el movimiento obrero que se conforma con las políticas de incentivo industrial, se centraliza en el noreste chubutense. El sujeto ambiental, en cambio, comienza a desarrollarse, como sujeto político, en la comarca andina asociada a la migración contracultural de la década del 70.

Pero el neoliberalismo marcó un quiebre a la dinámica antes mencionada. Como expresa Pérez Álvarez las particularidades regionales comenzaron a licuarse y a combinarse, no sólo al interior de la provincia, sino de la Argentina en general. Como se dijo anteriormente, en esta etapa es el capital financiero el que logra imponer sus intereses por sobre el conjunto de las fracciones burguesas. Si bien a nivel mundial comienza a principios de los 70, en Patagonia se comienza a manifestar a principios de los 90.

Este es otro momento bisagra en la que se debe hacer foco. Las políticas neoliberales dieron el marco a las privatizaciones de los bienes comunes, hasta ese momento sin explotar o explotados a pequeña escala, tal el caso del uranio ya mencionado en este trabajo. Este proceso, sumado a la crisis social general fue generando las condiciones para que toda la experiencia del movimiento obrero y la del ambientalismo se amalgamarán en contra de las contradicciones sociales y ambientales que se han ido profundizando, particularmente en su actual etapa de hegemonía financiera.

Es decir, en la década del 80 , pero con mayor claridad hacia mediados y fines de los 90 , se produce en la provincia una alianza entre sujetos subalternos alrededor de los problemas ambientales, los cuales hasta ese momento parecían escindidos, aun cuando son manifestación de las contradicciones que el capitalismo ha engendrado en la región. Como se dijo anteriormente, el No al Basurero Nuclear en Gastre (1983-1996) y el No a la Mina en Esquel (2003) serían las primeras a escala regional-provincial, que luego se irían potenciando con el No a la Mina del Proyecto Navidad en el presente y con el No a la Megaminería en general.

Se puede decir que el centro geográfico del movimiento ambiental a partir de la lucha contra el Proyecto Navidad (2009) se trasladó desde la Comarca Andina al noreste de la provincia, posiblemente por la conciencia ambiental que se fue desarrollando en este período. También se ha conjugado, como un factor clave, la vulnerabilidad en que se encuentra dicha región ante una posible contaminación de meseta, lugar por donde pasa el único río que abastece a más de la mitad de la población de Chubut (ver figura 1). Influye también que el noreste ha sido históricamente el centro político a nivel institucional, siendo la legislatura chubutense el lugar de disputa.

Con el movimiento ambiental como aglutinador, los sectores de trabajadores/as ocupados/as y desocupados/as, el sindicalismo antiburocrático, las organizaciones mapuche-tehuelches y la pequeña burguesía empobrecida, entre otros, comienzan a oponerse al modelo de acumulación por despojo de los bienes comunes. A su vez, y nutridos por el resto de las organizaciones del campo popular, el movimiento ambiental comienza a complejizar sus argumentos discursivos y sus estrategias de lucha. Así emergen discusiones centrales en torno al territorio, el agua, las cuencas, modelos productivos alternativos, despojo, e incluso al anticapitalismo. En este sentido, se cuestiona el funcionamiento del sistema democrático burgués y su marco para la connivencia corrupta entre políticos y empresarios. Es decir, un movimiento que comienza 
con inquietudes ecologistas, profundiza su conciencia en contacto con organizaciones sociales, sindicales y políticas.

\section{A MODO DE SÍNTESIS}

Como se ha podido observar, la constitución del movimiento ambiental tiene una larga trayectoria provincial, 1 a cual se consolidó como sujeto político de influencia nacional a partir de lo sucedido en Esquel en el año 2003. Esto es muy distinto a decir que el movimiento aparece con los hechos de Esquel, invisibilizando los procesos previos.

Como se ha expresado en este trabajo, la constitución de este sujeto político aparece a fines de la década del 70 por varios factores, entre ellos el contexto internacional, dada la descomposición de las condiciones de producción en los países industrializados y la aparición de movimientos sociales antisistémicos y contraculturales. En el contexto nacional se va a reflejar en la aparición del movimiento contracultural, denominado también como hippismo, que ha tenido, entre otras características, una fuerte preocupación por los problemas ecológicos, no sólo en términos teóricos sino también prácticos e incluso militantes. Las décadas del 60 y 70 se caracterizaron, en Latinoamérica, por la gran efervescencia político-social, y la alternancia de gobiernos democráticos y dictatoriales a nivel regional. En Argentina, la gran represión política y cultural desencadenó la migración, desde los grandes centros urbanos hacia la Comarca Andina, de un importante sector de estos movimientos contraculturales, en parte para poder desarrollar un modo de vida desligado de los patrones capitalistas. A su vez, el contexto local o provincial, imbuido en políticas desarrollistas, experimentó una explosión demográfica sin precedentes. Esto llevó a la complejización de las relaciones sociales, sindicales y políticas que existían antes de 1950, que a la postre fue el caldo de cultivo para la consolidación de fuertes movimientos obreros-sindicales y, posteriormente, ambientales.

En esta trayectoria del movimiento ambiental pueden distinguirse una serie de etapas. La primera es la aparición, como movimiento organizado, a fines de la década del 70 y principios del 80 . En dicho período el movimiento se caracterizó por tener una gran influencia local, sobre todo en las localidades más importantes de la Comarca Andina (El Bolsón, Lago Puelo y Epuyén). Un segundo período se inicia a mediados de la década del 80 hasta mediados de la década del 90, siendo las marchas a Gastre por el No al Basurero Nuclear (1986 y 1996) los hitos fundamentales. Este período se caracteriza por la influencia provincial del movimiento ambiental, incorporándose a la misma la región del Valle y la Costa o noreste del Chubut. Si bien es una hipótesis inicial, en este momento todavía no puede hablarse de un movimiento de confluencia multisectorial ya que, si bien algunos gremios y sindicatos acompañaban, la cuestión ambiental no estaba dentro de sus discusiones centrales. Un último período inicia a principios del siglo XXI hasta la actualidad. Aquí el movimiento ambiental provincial toma relevancia nacional e internacional, siendo una confluencia de diversos sujetos en lucha, desde sindicatos, organizaciones sociales y políticas, organizaciones de pueblos originarios, amalgamados en la Unión de Asambleas Ciudadanas. Hacia el año 2009, con la experiencia del Proyecto Navidad en la meseta central, el centro geográfico de la disputa se focaliza en la región noreste de la provincia, en gran medida por el potencial riesgo de contaminación al que se expone la cuenca del río Chubut y, por ende, la población que depende de sus aguas. Este río recorre el área en disputa hasta llegar a la costa, abasteciendo a las grandes ciudades del noreste (Trelew, Rawson, Puerto Madryn, entre otras). La conflictividad parece resonar con mayor fuerza al tratarse de la región que históricamente ha sido el centro político y sede de la legislatura provincial.

En síntesis, los motivos por los cuales la provincia del Chubut ha tenido esta trayectoria, y el por qué hoy sigue siendo un territorio difícil de cercar para el capital, deben ser abordados analizando factores estructurales pero también particulares. La correlación entre las contradicciones sociales y ambientales presente en las relaciones de producción no puede entonces estar ausente a la hora de analizar los procesos de conflicto y movilización que involucran demandas ambientales y territoriales. 
Resta indagar cuál será el legado de las resistencias, es decir, si se puede llegar a construir alguna alternativa política. Por lo pronto, como expresa James O 'Connor, los movimientos ambientales (así como los obreros, urbanos y otros), al luchar por proteger las condiciones de producción (o condiciones de vida), por restaurarlas o por ayudar a decidir cómo se las reestructurará durante períodos de crisis, pueden tener el efecto no deseado, para el poder económico, de elevar los costos y reducir la flexibilidad o libertad del capital, poniendo en peligro o lesionando así la acumulación capitalista. Retomando ideas de O 'Connor, se puede decir que el movimiento obrero sindical de los países industrializados, en su momento y hasta su pacto con el capital, empujó al capitalismo hacia formas más sociales de fuerzas y relaciones de producción, por ejemplo, con la negociación colectiva. Tal vez, el movimiento feminista, los movimientos ambientales y otros nuevos movimientos sociales puedan estar empujando al capital y al Estado hacia formas más sociales de la reproducción de las condiciones de producción (Galafassi 2012b).

\section{BibLiografía}

Bellamy Fosters, J. (1992). La ley general absoluta de la degradación ambiental en el capitalismo. Ecología Politica. Cuadernos de debate internacional, 4 ( $2^{\circ}$ semestre), 167-169

Borón, A. (2013). América Latina en la geopolitica del imperialismo [3 $3^{a}$ edición]. Argentina: Ediciones Luxemburg. Chiappe, L. (2004). La Patagonia de pie. Ecología vs Negociados. El Bolsón: Imprenta de Edgardo Suarez y familia.

Galafassi, G. y Riffo, L. (2018) Del sueño de Cristóbal Colón al hoy llamado “extractivismo”. Revista Theomai, 38, 231-245.

Galafassi, G. (2014). Procesos de construcción socia de los conflictos y modos de acumulación. Una correlación necesaria. En Galafassi, G. (Comp.), Apuntes de acumulación: capital, estado y procesos sociohistóricos de reproducción y conflictividad social. Argentina: Extramuro Ediciones.

Galafassi, G. (2012). Renovadas versiones de un proceso histórico en marcha. La predación del territorio y la naturaleza como acumulación. Revista Theomai, 25, 1-14.

Galafassi, G. (2012b). ¿Qué hay de nuevo, viejo? Procesos de movilización y conflictos socio-ambientales. Conflicto Social, 5 (8), 8-40.

Harvey, D. (2007). El nuevo imperialismo. Colección cuestiones de antagonismos. España: Editorial Akal.

Hermosilla Rivera, C. (2013). Población rural en Chubut: la meseta desde principio de siglo XX a la actualidad. Revista Párrafos Geográficos. Universidad Nacional de la Patagonia, 12 (1), 40-64

Lowy, M. (2011). Ecosocialismo. La alternativa radical a la catástrofe capitalista. Buenos Aires: Editorial El Colectivo. Herramienta ediciones.

O'Connor, J. (2001). Causas Naturales. Ensayos de marxismo ecológico. México: Editorial Siglo XXI.

Pérez Álvarez, G. (2013). Patagonia. Conflictividad social y neoliberalismo. El noreste del Chubut (1990-2005). Argentina: Imago Mundi.

Rodriguez Pardo, J. (2006). En la Patagonia NO. Crónica de una epopeya antinuclear en Gastre. El Bolsón: Proyecto Lemú ediciones.

Svampa, M. y Antonelli, M. (eds). (2009). Minería transnacional, narrativas del desarrollo y resistencias sociales. Argentina: Editorial Biblos. 